\title{
História e passado em
}

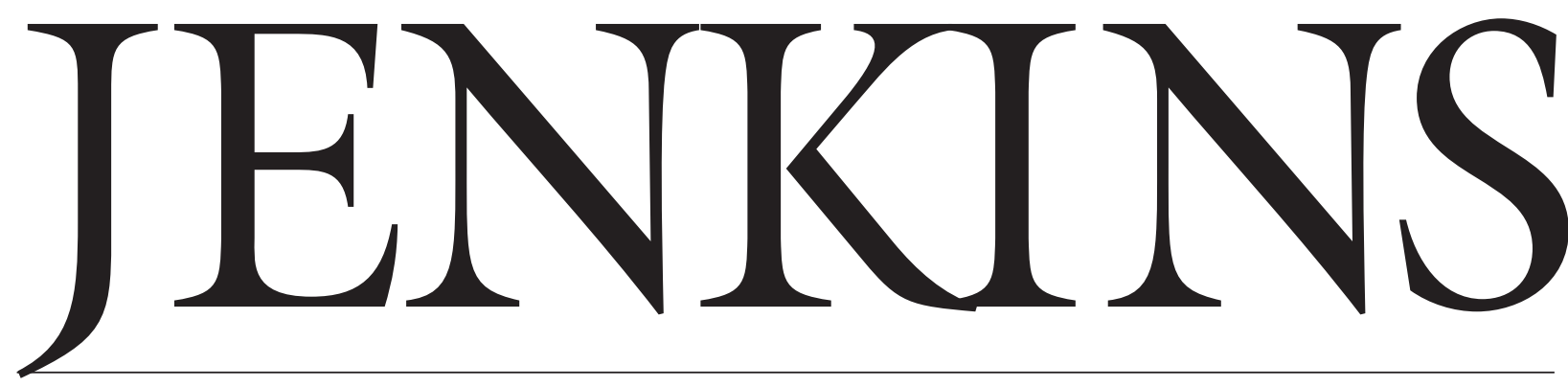

\section{JOÃO RICARDO DE CASTRO CALDEIRA}

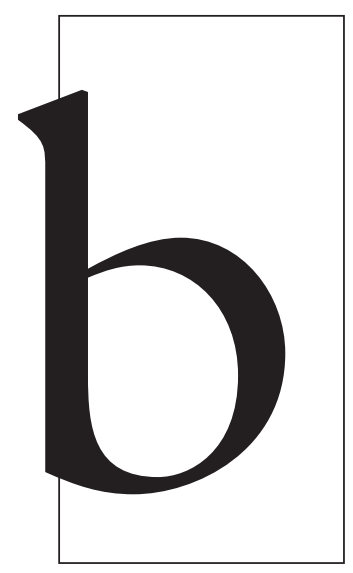

JOÃO RICARDO

DE CASTRO CALDEIRA

é doutor em História

Social pela USP, professor da UniABC e autor de Integralismo e Política

Regional (Annablume).

A História Repensada, de Keith Jenkins, tradução de Mário Vilela, São Paulo, Contexto, 2001. astante oportuna a publicação, pela Editora Contexto, da tradução do livro Re-Thinking History, de autoria do historiador inglês Keith Jenkins, sobretudo se levarmos em consideração a relativa ausência, no Brasil, “de textos teóricos acessíveis, diretos e elucidativos" a respeito dos mais recentes debates no campo da historiografia, como afirma a professora Margareth Rago na apresentação da obra (p. 9).

Com efeito, nas últimas décadas do século XX, as discussões sobre a posição da história na área das ciências humanas suscitaram o aparecimento de perspectivas diversas.

Tais debates, observe-se, têm se centrado especialmente na crítica à concepção de história elaborada no século XIX (que se constituiu visão oficializada do passado), construída principalmente a partir de interpretações da sociedade européia industrializada. Fundamentadas nessa história eurocêntrica e cientificista, foram desenvolvidas, à luz de explicações sobre o passado, teorias que pretenderam desvendar o sentido da 
evolução de toda a humanidade, como o positivismo e o marxismo. Exemplos da crítica a tais pretensões totalizantes encontram-se sobretudo no pensamento de Benedetto Croce, R. G. Collingwood, Claude Lévi-Strauss e Michel Foucault. Os dois primeiros, conhecidos teóricos da história; os últimos, eméritos cientistas sociais.

Com efeito, Croce e Collingwood, no início do século XX, estabeleceram a distinção entre a história enquanto a totalidade dos eventos passados e a historiografia, ou seja, a história produzida por um autor, no caso, o historiador. Conforme essa perspectiva, a historiografia seria o resultado das visões de mundo do historiador. Noutros termos, de acordo com Croce e Collingwood, evidencia-se aí uma recusa da idéia do alcance da plena objetividade na produção historiográfica.

Por outro lado, mais recentemente, LéviStrauss e Michel Foucault ressaltaram, em trabalhos diversos, que a história, como as demais ciências humanas, não ultrapassa a condição de discurso sobre os homens e o mundo, assemelhando-se assim às demais práticas discursivas que os representam nas diferentes sociedades humanas. Portanto, ciência (incluindo a história) e mito desempenhariam papéis similares, enquanto narrativas que conferem significado ao mundo e às ações dos homens.

Esses questionamentos, que em tempos recentes começaram a influenciar certos círculos acadêmicos, têm em Keith Jenkins um dos seus mais expressivos expoentes.

Jenkins pertence a um grupo de historiadores da Inglaterra e dos Estados Unidos (Hayden White, David Lowenthal, Stephen Bann) cuja produção, surgida a partir da década de 1970, é razoavelmente influenciada pelas idéias de Croce, Collingwood, Lévi-Strauss e Foucault. Em síntese, o pensamento desses historiadores caracterizase pela crítica ao cientificismo, ao eurocentrismo e à ambição totalizante da história na investigação do passado. Seu posicionamento aponta ainda para a necessidade de relativizar a distinção entre ficção e história, ressaltando o caráter literário da obra historiográfica. Incluem-se eles, portanto, entre os autores da chamada historiografia da pós-modernidade.

Em A História Repensada, Keith Jenkins formula proposições que são próprias dessa corrente de historiadores à qual se vincula. O livro se apresenta dividido em três capítulos: no primeiro, o autor procura responder à pergunta: “ 'o que é a história?' ', ressaltando a ambigüidade desse conceito; no segundo, aborda temas relativos à cientificidade da história, concentrando sua atenção em questões como a possibilidade da objetividade e a influência da parcialidade (bias, no original em inglês) no trabalho historiográfico; no terceiro e último capítulo, discute a produção histórica na pós-modernidade.

Ao conceituar a história, ele a considera "um dentre uma série de discursos a respeito do mundo', enfatizando que esses discursos não criam o mundo, mas "se apropriam do mundo e lhe dão todos os significados que tem', (p. 23). Como se vê, sob esse aspecto, é forte a influência de Foucault e Lévi-Strauss sobre o autor.

Quanto à relação entre a história e seu objeto (o passado), Jenkins estabelece uma diferenciação entre ambos do seguinte modo: "passado e história são coisas diferentes", (p. 24). Para o autor, o passado é todo o acontecido em qualquer tempo e lugar, não podendo ser revisitado nem recuperado: "o mundo ou o passado sempre nos chegam como narrativas e [...] não podemos sair dessas narrativas para verificar se correspondem ao mundo ou ao passado reais, pois elas constituem a 'realidade"” (p. 28). Por isso, para esse autor, a história não corresponde ao passado que ela se propõe recuperar. Em sua perspectiva, "história (historiografia) é um constructo lingüístico intertextual" (p. 26), resultado da elaboração, pelo historiador, de um discurso que, ao se propor recuperar o passado, apenas o representa, empregando recursos lingüísticos através dos quais lhe confere significado.

Para ilustrar que o aprendizado da história constitui simplesmente a assimilação das idéias dos historiadores, Jenkins escreve com algum humor: 
“Digamos que você esteja estudando parte do passado inglês (o século XVI, por exemplo) no secundário britânico. Vamos imaginar que você use um renomado compêndio: England under the Tudors, de Geoffrey Elton. Na aula em que se trata de aspectos do século XVI, você faz anotações em classe. Mas, para os trabalhos e o grosso da revisão da matéria, usa Elton. Na hora do exame, escreve à sombra de Elton. Ao passar, está aprovado em história inglesa, ou seja, está qualificado na análise de certos aspectos do 'passado'. No entanto, seria mais acertado dizer que você passou não em história inglesa, mas em Geoffrey Elton - pois, nessa fase, o que é sua 'leitura' do passado inglês senão uma leitura de Elton?" (p. 26).

Apesar de longa, a citação acima é cabível, sobretudo por ser bastante elucidativa da posição de Jenkins frente à questão da relação entre a história e o passado. Com efeito, na sua perspectiva, a história “é menos que o passado', (p. 34), do qual só é possível recuperar fragmentos, que são selecionados e agrupados pelos historiadores conforme seus objetivos e interesses. Tais fragmentos passam, então, a constituir a matéria-prima com a qual, utilizando suas ferramentas metodológicas e analíticas, e empregando recursos lingüísticos e literários, os historiadores escrevem os textos que constituem o que denominamos história. Desse modo, esta não ultrapassa a condição de representação do passado, uma construção pessoal, fruto da perspectiva do historiador enquanto narrador, como no caso de Geoffrey Elton em relação ao século XVI na Inglaterra.

Ao assim se posicionar, Jenkins admite que o historiador é, simultaneamente, o investigador e o construtor do seu objeto, negando-lhe portanto a possibilidade de explicar aquilo que ele mesmo constrói. Ressalte-se ainda que, para esse autor, a empatia, ou seja, o conhecimento do outro (pertencente a outro tempo e lugar) por parte do historiador é impossível, na medida em que as “ "interpretações do passado [são] elaboradas no presente'” (p. 40). Observase, nesse ponto, a aproximação de Jenkins com as perspectivas de Croce e Collingwood.

Entretanto, ainda que recuse a possibilidade da explicação em história, Jenkins reconhece a validade do discurso historiográfico enquanto narrativa que confere significado aos acontecimentos pretéritos, pois estes, de acordo com esse autor, são melhor conhecidos quando vistos em retrospecto.

Jenkins acentua ainda que, assim como há múltiplas perspectivas possíveis às quais os historiadores podem recorrer ao elaborarem representações do passado, os acontecimentos por eles narrados também podem ser objeto de leituras diversificadas. De algum modo, o autor alerta para a necessidade da relativização na análise historiográfica.

Quanto à questão da produção historiográfica, ao final do livro o autor apresenta sua sugestão de um modo de fazer história no mundo pós-moderno, propondo "uma historização radical da história', tomada como ponto de partida para o subseqüente trabalho histórico. Nesse sentido, Jenkins afirma que, no mundo pós-moderno, devese escolher " "entre uma história que está consciente do que faz e uma história que não está', (p. 106).

O livro de Jenkins se apresenta ao leitor como um importante conjunto de proposições e discussões sobre o conceito de história e seu objeto, bem como sobre a relação entre ambos, constituindo importante referência para estudantes, professores e pesquisadores de história. 